\title{
Rehabilitación Urbana y Gentrificación en el Barrio de Chueca: la Contribución Gay
}

\author{
Urban Rehabilitation and Gentrification in the Neighborhood of Chueca: Gay \\ Contribution
}

\section{Renaud René Boivin ${ }^{1}$}

Instituto Francés de Urbanismo

renoboivin@yahoo.es

\section{Resumen}

El artículo hace una revisión de los vínculos entre el proceso de gentrificación del barrio madrileño de Chueca y la presencia homosexual. Según se plantea, Chueca ya estaba en el epicentro homosexual y travestí desde décadas atrás. Se argumenta además que la actividad empresarial gay y la atracción residencial de los años 90 y 2000 , por sí solas no explican la participación de la población gay y lesbiana en el proceso de gentrificación y en la rehabilitación del barrio. Es necesario dirigir la mirada hacia las representaciones del varón homosexual, hacia los cambios en sus modos de vida, para aprehender las modificaciones de la imagen de Chueca.

Palabras claves: Rehabilitación; Gay; Gentrificación; Chueca; Comercio.

\section{Abstract}

This paper reviews the links between the gentrification process of the Madrilenian district of Chueca and homosexual presence. As envisioned, Chueca already was in the gay and transvestite epicenter from decades ago. It is further argued that the gay business and residential attraction of the 90's and 2000's alone do not explain the participation of gay and lesbian population in the process of gentrification and neighborhood rehabilitation. It is necessary to look at representations of the male homosexual, to the changes in their lifestyles, to grasp the changes in Chueca image.

Keywords: Rehabilitation; Gay; Gentrification; Chueca; Trade. 


\section{Gentrificación en el barrio gay}

El término 'gentrificación' fue acuñado por Ruth Glass en 1964 en su estudio de la gentry londinense para nombrar la vuelta al centro histórico de dicha clase, la cual representaba una inversión de sus estrategias residenciales tradicionales. La noción fue retomada en los años 70 por geográfos de inspiración marxista para describir el proceso de sustitución de las clases obreras por clases medias-altas en zonas degradadas y abandonadas de la ciudad, mismo proceso que se hallaba ligado a los programas públicos de rehabilitación urbana. La gentrificación es un fenómeno sumamente complejo, ligado a factores de índole socio-cultural (centralidad del ocio), económico-espacial (internacionalización, auges de los sectores financiero e inmobiliario) y político (políticas públicas hacia la conservación del centro urbano, necesidad de paliar el déficit presupuestario en éste). Además del recambio poblacional (desplazamiento de las familias que no puedan enfrentar los nuevos costes), la gentrificación se caracteriza por una modificación estructural del mercado de vivienda (rehabilitación, aumento de ocupantes-propietarios, alza de precios); la transformación de la imagen de la zona, gracias a una mayor inversión en infraestructuras y equipamientos $\mathrm{y}$, por último, por un cambio en la tipología de comercios, menos orientados a las necesidades de la población local.

Desde el estudio pionero de Manuel Castells (1983) en San Francisco, la participación de las poblaciones gays en los procesos de gentrificación y de rehabilitación de los centros urbanos ha sido objeto de varias investigaciones empíricas en el medio académico anglosajón (BOUTHILLETTE, 1994; KNOPP, LAURIA, 1985; KNOPP, 1990) mientras que, en cambio, dicha contribución apenas se empieza a mencionar en los estudios urbanos europeos y latinoamericanos. Algunos trabajos sobre gentrificación evocan el atractivo del ambiente gay para otros sectores (CHICOINE, ROSE, 1998), sin profundizar sobre la relación entre la presencia residencial y/o comercial gay y dicho proceso. Ahora bien, la gentrificación y la constitución de 'barrios gays' son fenómenos que aparecieron de forma coetánea en las ciudades estadounidenses en los años 70 , y se retroalimentan en una multiplicidad de casos desde los 80. El sociólogo Pollak (1982, p.48) ya se interrogaba sobre este repliegue en el gueto gay, donde "Los homosexuales representan la mayoría de la población, controlan buena parte de los comercios, en particular los bares, el mercado inmobiliario y parte del mercado de trabajo". Dicho gueto gay es el producto de una doble segregación, tanto sexual como social, ya que "sólo representa una minoría de todos los homosexuales, y la transformación de la condición homosexual que halló su origen en las clases medias urbanas no implica a todo el mundo", según apuntan Pollak y Schiltz (1987, p.85).

Al igual que el Marais en París, el caso de Chueca ${ }^{2}$ se tornó un ejemplo paradigmático de gentrificación gay al haber sido un barrio muy degradado materialmente y aún más deteriorado simbólicamente para, en los años 2000, volverse rápidamente una zona ennoblecida y turística a la vez que un centro de comercios LGBT. En estos dos casos, la política urbana, de rehabilitación de espacios públicos, edificios y alojamientos, parece haber sido una estructura de oportunidad para la atracción de la población gay, la cual se constituyó así como pionera del 'redescubrimiento' de un barrio popular, y activó un proceso de gentrificación muchas veces a su propio pesar. La administración pública y los académicos comparten la convicción de que existe un potente proceso de gentrificación en Chueca, y que éste es una consecuencia de las acciones de rehabilitación de viviendas y revitalización comercial llevadas a cabo por las poblaciones gays ${ }^{3}$. No obstante, no existe ningún trabajo publicado que estudie tal relación, ni siquiera que proporcione datos empíricos sobre la gentrificación en $\mathrm{si}^{4}$.

Algunos autores relacionan directamente la gentrificación con la llegada de población gay en el barrio, como el geógrafo Barrado Timón (2008, s/p) en su análisis del turismo en Madrid, quien sin mediar argumentos plantea que "Chueca (...) ha experimentado un proceso de gentrificación en gran medida por parte de población homosexual, lo que favoreció además la aparición de un sector comercial y de ocio especializado". García Escalona (2000), especializada en geografía del consumo, recoge la representación mediática del gay liberado y de dinero - como si la homosexualidad sólo fuera cuestión de mercado - y admite sin ninguna averiguación que el barrio gay madrileño nació en los 90 como consecuencia de los esfuerzos y actividades del movimiento cultural gay y de la instalación residencial de individuos homosexuales. Centrándose en los "símbolos gays" presentes en el barrio, la autora concibe la visibilidad gay como una ganancia en el terreno de la aceptación social de la homosexualidad (GARCÍA ESCALONA, 2000, p. 448).

Las publicaciones gays madrileñas de los años 80 abundan en información sobre el desarrollo del ambiente gay. Su lectura permite constatar que las condiciones requeridas para la formación del 'barrio gay' -esto es: concentración residencial, visibilidad geográfica, actividad comunitaria, estructura 
organizativa de comerciantes y residentes así como 'soporte financiero', según García Escalona- se reunieron ya en tiempos de la Movida, aunque a un nivel mucho menor. Por otra parte, la autora no demuestra la existencia de una concentración residencial homosexual, la cual constituye un elemento de suma importancia (quizás más que el ingrediente económico) para dar al barrio un sentido compartido. En definitiva, repite las representaciones políticamente correctas de la prensa nacional y reproduce una concepción neoliberal muy presente en ella. Ésta consiste en pensar que el llamado 'dinero rosa' permite e ilustra la 'liberación gay', hipótesis que no está comprobada.

Fernández Salinas (2007, p. 245), de la Universidad de Sevilla, hace hincapié en la visibilidad como elemento estructurador del estudio de la cultura gay en relación con el espacio urbano. Aunque afirma que "el grado de inserción social de las comunidades gay cuando asumen su condición sexual de manera abierta y natural es un proceso de difícil medición", a partir de las cifras de establecimientos comerciales gays, el geógrafo propone un 'modelo básico' que relaciona los grados de 'visibilidad gay' con territorios ${ }^{5}$ progresistas. Para él, cuanto mayor es la concentración de lugares comerciales en un territorio, más aceptada es la homosexualidad en éste. En Madrid, la 'visibilidad amplia' -es decir, la mayor concentración comercialsería así sinónima de una mayor tolerancia hacia la población homosexual. Ahora bien, no se puede, a través de una guía internacional como Spartacus, saber si un sitio es realmente visible o no, ni tampoco si las personas que lo frecuentan han salido del clóset o si se ocultan en un espacio específico precisamente por no poder expresar públicamente su orientación sexual en otros ámbitos sociales y urbanos. Además, muchas guías y revistas publican información de sitios mixtos o que poco tienen que ver con la cultura gay, al ser no pocas veces fruto de lógicas empresariales ${ }^{6}$. Por otra parte, la guía Spartacus puede indicar establecimientos 'gays' frecuentados únicamente por un público internacional. Por último, este tipo de análisis cuantitativo no aporta ningún dato sobre las maneras en que los usuarios se apropian el espacio y viven su homosexualidad, ni tampoco permite saber si esta visibilidad es realmente sinónima de una mayor aceptación social de la homosexualidad fuera de estos lugares donde se refugia.

Santos Solla (2002, p.74) se aleja de este tipo de generalizaciones al manejar la hipótesis de que los gays han sido "absorbidos por el sistema". Según explica, "Una cierta tolerancia hacia lo que hasta hace poco era definido como enfermedad, perversión (...), ha hecho que muchos gays y lesbianas abracen con gusto ese nuevo estatus social renunciando a muchos de los cambios que en su momento estimularon al movimiento homosexual". En efecto, "la visibilidad es llevada a casi todos los campos e incluso los barrios gays son admirados como ejemplos de recuperación urbana. Todo esto ha generado un sentimiento de asimilación (...)". Como bien apunta, la rehabilitación urbana también incentiva procesos de especulación que a su vez engendran desplazamientos de la población con menores recursos. Así pues, más que un espacio de libertad y apertura, es un 'gueto' que permite a los gays y lesbianas refugiarse de la homofobia y del heterosexismo que estructuran el resto de los contextos socio-urbanos: "de esta manera, la homosexualidad se mantiene invisible en muchas áreas o se convierte en una cuestión muy minoritaria, dificultando así la visibilidad de los que quedan" (SANTOS SOLLA, 2002, p.74).

\section{La gentrificación de Chueca: algunos indicadores}

Como otros barrios del Centro madrileño, en los años 70 Chueca perdió población joven activa $\mathrm{y}$ experimentó un proceso de envejecimiento, degradándose cada vez más su parque de vivienda, abandonado por los propietarios no residentes y los poderes públicos. Podemos situar el inicio de la primera fase de gentrificación del barrio a mediados de los años 80, en un momento de incremento de la segregación residencial, al incorporarse Madrid a la internacionalización de la economía - con la entrada de capitales extranjeros en el mercado inmobiliario y financiero, tras y gracias al ingreso de España a la Unión Económica Europea, en 19867.

En Chueca, entre 1991 y 2001, el parque de vivienda experimenta profundos cambios, que se reflejan en el aumento de la desocupación y el incremento de la proporción de viviendas secundarias (en un $72 \%$ y $150 \%$ respectivamente), factores que sin duda están ligados a la rehabilitación urbana y a la especulación descontrolada que ésta conllevó. Podemos afirmar que la política de rehabilitación urbana, que consiste en subvencionar parte de las obras comunes o individuales de acomodación y ampliación de las viviendas, no permitió reponer en el mercado los alojamientos vacíos y/o defectuosos. Por otro lado parece haber incentivado a los propietarios a adaptar las viviendas a las nuevas demandas en términos de estándares y superficies: los estudios y las viviendas de dos habitaciones aumentan respectivamente un $65 \%$ y $44 \% \%^{8}$. Finalmente, en los años 90 y principios del siglo XXI se eleva

Renaud René Boivin 
drásticamente el precio del $\mathrm{m} 2$ en la zona, de una manera relativamente más intensa que en el resto del Centro de Madrid (MUÑOZ, 2009).

En la primera fase del proceso (1986-1996) ${ }^{9}$, siguen saliendo familias (matrimonios con hijos), hipotéticamente en busca de mejores condiciones de hábitat y hacia zonas de mayor prestigio social: el abandono y la degradación, la delincuencia callejera, la crisis económica y social $^{10}$, llevarían a un serie de desplazamientos en cadena. El envejecimiento se acentúa: la población mayor de 65 años llega a representar un cuarto de los residentes en 1996, mientras que la proporción de niños y jóvenes adultos sigue disminuyendo. En la segunda fase, a partir de 1996 aproximadamente, el barrio empieza a volverse atractivo para estudiantes y jóvenes activos (grupos de 25-44 años), con una preparación escolar más elevada; un claro indicio de gentrificación (tabla 1) grupos en edades activas es menor que en Madrid, por lo que se estabiliza, en cierto modo, el proceso de recambio de población. Así pues, tras varios años de crisis aguda, el barrio parece volver a recobrar vida a partir de 1994 o 1995. La fecha coincide con la firma de los Convenios de Rehabilitación entre el Ministerio de Vivienda, la Comunidad de Madrid y el Ayuntamiento, los cuales permiten subvencionar parte de las obras de acomodación y reparación. Coincide también con la decisión de Mili Hernández, quien encabeza el Colectivo Gay de Madrid (COGAM) tras diez años de separación entre varones y mujeres, de trasladar la sede del movimiento lésbico-gay madrileño, a la vez que su librería, al barrio de Chueca.

Las nuevas estrategias discursivas del movimiento LGBT madrileño tienen repercusiones en el espacio. Los militantes del primer movimiento gay madrileño criticaban la concentración comercial en el barrio y

Tabla 1: Población de hecho por grandes grupos de edad, Justicia y Madrid, 1986-2006 (porcentajes del total)

\begin{tabular}{|c|c|c|c|c|c|c|c|c|c|c|}
\hline \multirow{2}{*}{$\begin{array}{l}\text { Grupos de } \\
\text { edad }\end{array}$} & \multicolumn{2}{|c|}{1986} & \multicolumn{2}{|c|}{1991} & \multicolumn{2}{|c|}{1996} & \multicolumn{2}{|c|}{2001} & \multicolumn{2}{|c|}{2006} \\
\hline & Justicia & Madrid & Justicia & Madrid & Justicia & Madrid & Justicia & Madrid & Justicia & Madrid \\
\hline $0-14$ años & $11 \%$ & $19 \%$ & $10 \%$ & $15 \%$ & $9 \%$ & $13 \%$ & $9 \%$ & $12 \%$ & $10 \%$ & $13 \%$ \\
\hline 15-24 años & $15 \%$ & $18 \%$ & $13 \%$ & $17 \%$ & $11 \%$ & $15 \%$ & $10 \%$ & $12 \%$ & $8 \%$ & $10 \%$ \\
\hline 25-34 años & $15 \%$ & $13 \%$ & $18 \%$ & $16 \%$ & $17 \%$ & $17 \%$ & $20 \%$ & $18 \%$ & $22 \%$ & $18 \%$ \\
\hline 35-44 años & $10 \%$ & $12 \%$ & $12 \%$ & $12 \%$ & $15 \%$ & $13 \%$ & $18 \%$ & $16 \%$ & $20 \%$ & $17 \%$ \\
\hline 45-54 años & $11 \%$ & $13 \%$ & $10 \%$ & $12 \%$ & $11 \%$ & $12 \%$ & $13 \%$ & $12 \%$ & $13 \%$ & $13 \%$ \\
\hline 55-64 años & $14 \%$ & $12 \%$ & $13 \%$ & $13 \%$ & $12 \%$ & $12 \%$ & $10 \%$ & $11 \%$ & $10 \%$ & $11 \%$ \\
\hline $65 y+$ & $23 \%$ & $13 \%$ & $23 \%$ & $15 \%$ & $24 \%$ & $18 \%$ & $21 \%$ & $19 \%$ & $18 \%$ & $19 \%$ \\
\hline Total & $100 \%$ & $100 \%$ & $100 \%$ & $100 \%$ & $100 \%$ & $100 \%$ & $100 \%$ & $100 \%$ & $100 \%$ & $100 \%$ \\
\hline
\end{tabular}

Fuente: Elaboración propia a partir de los Censos de Población y Padrón Municipal, Instituto de Estadísticas de la Comunidad de Madrid

En efecto, si bien ya en 1986 hallábamos una mayor proporción de personas con niveles altos de estudios en comparación con el conjunto del municipio, tal diferencia no sólo se mantiene a lo largo de los veinte últimos años, sino que tiende a agrandarse en la última década, debido a la llegada de una población con un capital cultural más alto (tabla 2).

La sustitución por poblaciones de 35-44 años empieza a verse claramente a partir de 1996. Los nuevos llegados ocupan así las viviendas abandonadas por las poblaciones mayores o en un nivel más avanzado de su ciclo familiar. A partir de 2001, la tendencia se mantiene pero en el aumento relativo de ponían en evidencia la contradicción entre la existencia de un "ghetto comercial autorizado oficialmente para uso exclusivo de los homosexuales" y la negativa al derecho de asociación para los mismos (El País, 16/05/1979). El término 'gueto' empezó a ausentarse del lenguaje de los militantes cuando, para combatir el estigma ligado al VIH-Sida, a principios de los 90 el COGAM pasó a reivindicar la concentración comercial gay y trabajar para la realización de un una especie de espacio de liberación en Chueca. El mismo discurso de los comerciantes -que son a la vez, algunos de ellos, militantes- edifica una visión de la historia local en la que ellos han 'recuperado' el barrio y han permitido una mayor

Renaud René Boivin 
visibilidad de los actores LGBT, abriendo cafés y tiendas de día, por ejemplo. La prensa recoge esta visión de zona libertaria desde mediados de los 90 . A partir de 1997, los redactores del periódico nacional de corte conservador $A B C$ cambian radicalmente su descripción de la homosexualidad y de Chueca, aplaudiendo a los gays, los cuales habrían convertido el gueto en una "zona rosa" limpiándolo de la delincuencia, permitiendo así su "crecimiento" (ABC, 07-02-97, 01-04-2000 y 30-06-01).

\section{La contribución de las poblaciones gays}

Las escasas referencias sobre gentrificación en Madrid describen las poblaciones gays como pioneras en los procesos revitalizadores de Chueca. Las poblaciones LGBT habrían sido las principales protagonistas del profundo cambio urbano experimentado por la zona, siempre concebido éste como una mejora a pesar de alimentar la salida de las poblaciones más vulnerables. Si bien es cierto que no

Tabla 2: Evolución del nivel de estudios en la población de 16 años y + en Justicia y Madrid, 1986-2001 (porcentaje del total)

\begin{tabular}{|c|c|c|c|c|c|c|c|c|}
\hline & \multicolumn{2}{|c|}{1986} & \multicolumn{2}{|c|}{1991} & \multicolumn{2}{|c|}{1996} & \multicolumn{2}{|c|}{2001} \\
\hline & Justicia & Madrid & Justicia & Madrid & Justicia & Madrid & Justicia & Madrid \\
\hline Sin estudios & $25 \%$ & $28 \%$ & $14 \%$ & $19 \%$ & $7 \%$ & $11 \%$ & $7 \%$ & $12 \%$ \\
\hline $\begin{array}{l}\text { Enseñanzas de } 1^{\circ} \text { y } 2^{\circ} \text { grado, } \\
\text { ciclo I }\end{array}$ & $34 \%$ & $38 \%$ & $37 \%$ & $41 \%$ & $40 \%$ & $43 \%$ & $33 \%$ & $39 \%$ \\
\hline Enseñanzas de $2^{\circ}$ grado, ciclo II & $23 \%$ & $22 \%$ & $25 \%$ & $24 \%$ & $26 \%$ & $25 \%$ & $26 \%$ & $25 \%$ \\
\hline Enseñanzas de $3^{\circ}$ grado, ciclo I & $5 \%$ & $5 \%$ & $6 \%$ & $6 \%$ & $9 \%$ & $10 \%$ & $10 \%$ & $9 \%$ \\
\hline $\begin{array}{l}\text { Enseñanzas de } 3^{\circ} \text { grado, ciclos II } \\
\text { y III }\end{array}$ & $13 \%$ & $8 \%$ & $16 \%$ & $10 \%$ & $17 \%$ & $11 \%$ & $23 \%$ & $15 \%$ \\
\hline \multirow[t]{2}{*}{ Total (población de + de 16 años) } & $100 \%$ & $100 \%$ & $100 \%$ & $100 \%$ & $100 \%$ & $100 \%$ & $100 \%$ & $100 \%$ \\
\hline & 15.915 & 2.434 .794 & 14.811 & 2.509 .020 & 13.128 & 2.466 .941 & 13.367 & 2.536 .656 \\
\hline
\end{tabular}

Fuente:Censos y Padrones, Instituto de Estadísticas de la Comunidad de Madrid, cálculos propios

Ahora bien, Chueca ya era un 'barrio gay' a principios de los 70, como bien indicaba Olano (1975) en su Guía secreta de Madrid, y el primer boom de establecimientos gays ocurrió a principios de los 80 . En 1986 el barrio ya concentraba el $54 \%$ de los comercios destinados exclusivamente a una población gay y lésbica de la ciudad ${ }^{11}$. Los gays y los travestís, los 'chaperos' (prostitutos) y sus clientes no ocultaban sus actividades. Su presencia en el barrio era ya muy evidente desde mediados de los 70. Más bien, parece ser que, durante los primeros años de la epidemia, el aumento de la delincuencia y de la mortalidad juvenil/masculina, la represión policial y el violento acoso de grupos de ultraderecha hacia las y los travestis, transexuales, gays y lesbianas que frecuentaban el barrio, han hecho desaparecer, en parte en la realidad y por otra en las representaciones, el movimiento anterior de recuperación del barrio como espacio público, abierto, ambiguo, de mezcla, encuentro y experimentación de los tiempos de la Movida. existen datos estadísticos precisos sobre residentes gays y lesbianas, podemos utilizar un indicador de la presencia homosexual a partir de los datos de población en hogares del Censo de 2001, en los que por primera vez se contabilizaron como núcleos familiares las parejas del mismo sexo. La tabla 3 permite constatar así que las parejas homosexuales se concentran en Justicia, junto con Embajadores y Universidad, donde la proporción de uniones libres entre personas del mismo sexo en relación con el total de parejas de hecho es muy superior a la media madrileña (de $0,2 \%$ ) y en los cuales se afincan casi un $1 / 4$ de las parejas gays y lesbianas de la ciudad. Estos datos quedan confirmados por la mayor frecuencia en estos barrios de matrimonios entre personas del mismo sexo en 2005, 2006 y 2007. Tomando en cuenta que el tamaño poblacional del barrio de Justicia es relativamente más reducido respecto de los demás barrios, la concentración residencial de matrimonios gays es proporcionalmente superior en aquél. Los barrios de Embajadores, Universidad y Justicia/Chueca son precisamente los que experimentaron procesos de

Renaud René Boivin 
gentrificación de mayor calado en el Distrito Centro. Esto último no significa que la población de orientación homosexual tenga mayor poder adquisitivo que las parejas heterosexuales, sino que una fracción privilegiada de ésta, al igual que otros grupos de clase media atraídos por la centralidad, de mayores capitales cultural y/o económico, hacen el cálculo de instalarse cerca de los lugares de ocio y cultura que frecuentan (MUÑOZ, 2009). alimentándose, seguramente, estos factores) o, por último, para responder a la mayor competencia que propicia la concentración espacial, se distinguen unos de otros y se especializan cada vez más en términos de públicos y ambientes. No es, pues, que el homosexual se haya hecho más visible en este paso entre la socialización en la calle y la sociabilidad de los bares y discotecas, sino que el discurso gay, su representación del espacio y de la homosexualidad, se modificaron en

Tabla 3: Parejas del mismo sexo (2001)* y matrimonios entre personas del mismo sexo (2005-2007) por barrios de Madrid

\begin{tabular}{|c|c|c|c|c|c|c|}
\hline & $\begin{array}{c}\text { Parejas en } \\
\text { hogares de un } \\
\text { núcleo (total) }\end{array}$ & $\begin{array}{c}\text { Parejas de } \\
\text { distinto sexo }\end{array}$ & $\begin{array}{l}\text { Parejas del } \\
\text { mismo sexo, } \\
\text { total }\end{array}$ & $\begin{array}{c}\% \text { parejas del } \\
\text { mismo } \\
\text { sexo/total } \\
\text { parejas en el } \\
\text { barrio }\end{array}$ & $\begin{array}{c}\% \text { parejas del } \\
\text { mismo } \\
\text { sexo/total } \\
\text { parejas mismo } \\
\text { sexo en Madrid }\end{array}$ & $\begin{array}{c}\% \text { matrimonios } \\
\text { gay } 2005- \\
2007 / \text { total en } \\
\text { Madrid }\end{array}$ \\
\hline Palacio & 3.592 & 3.546 & 46 & $1,3 \%$ & $3,2 \%$ & $2,6 \%$ \\
\hline Embajadores & 6.765 & 6.616 & 149 & $2,2 \%$ & $10,2 \%$ & $4,1 \%$ \\
\hline Cortes & 1.487 & 1.465 & 18 & $1,2 \%$ & $1,2 \%$ & $1,5 \%$ \\
\hline Justicia & 2.309 & 2.235 & 74 & $3,2 \%$ & $5,1 \%$ & $4,4 \%$ \\
\hline Universidad & 4.563 & 4.463 & 100 & $2,2 \%$ & $6,9 \%$ & $5,7 \%$ \\
\hline Sol & 989 & 971 & 13 & $1,3 \%$ & $0,9 \%$ & $3,7 \%$ \\
\hline
\end{tabular}

* Sólo se muestran los resultados para los barrios con un porcentaje de parejas del mismo sexo en relación con el $\mathrm{n}^{\mathrm{o}}$ total de parejas superior a $1 \%$

Fuente: Elaboración propia a partir de la población en hogares con 1 núcleo, Censo de 2001, Instituto de Estadísticas de la Comunidad de Madrid

\section{La gentrificación comercial, reflejo de los cambios en los modos de vida del homosexual}

Con la llegada de un discurso público gay propio en los años 70, y aún más con la aparición del sida a mediados de los 80, los lugares de homosocialización se especializan para recibir a una población homosexual que a su vez se identifica cada vez más con el modelo gay, el cual supone a su vez una mayor territorialización y la institucionalización de las sociabilidades homosexuales, según observaba Guash (1995). Por otra parte, a esta transformación sucedieron nuevos cambios en los modos de vida de la población homosexual, los cuales se reflejan en Chueca, siendo la gentrificación comercial actual del barrio fruto de tales cambios (BOIVIN, 2010a).

La gentrificación comercial del barrio gay es la expresión de dos dinámicas confluyentes: además de ser el efecto de los cambios en las prácticas sociosexuales y en los modos de vida homosexuales a raíz de la epidemia, es la consecuencia de intenciones e intereses de algunos comerciantes, quienes, tanto por dar una imagen más positiva y exitosa del gay como para asegurar sus propias ganancias económicas (retro- estos veinte años, llegando a provocar una verdadera amnesia en relación a las dos décadas anteriores, en las cuales Chueca se conformó como centro de la actividad travestí, de ligue homosexual y de prostitución masculina, aunque fuera a partir de las calles traseras, los baños del bar Oliver y del Café Gijón, las salas travestís o, más discretamente, en las ancestrales tabernas del barrio. Con la crisis del sida, tanto para combatir la enfermedad como para enfrentarse al estigma, los comerciantes y militantes gays empiezan a entretejer nuevas relaciones de colaboración, estrechamiento que podemos seguir en los medios especializados: la creación en 1997 de Zero, 'la primera revista de información y estilo de vida gay' según rezaba su subtítulo, es la materialización de estas nuevas relaciones. En su producción participan militantes, comerciantes y otros empresarios gays, así como homosexuales del mundo intelectual y artístico. Esta unión entre política, cultura y mercado gays propicia así la consolidación y unificación de un discurso homosexual, hecho de nuevas representaciones y valores.

A partir de finales de los 80, la desaparición o disimulación de los ingredientes vinculados con el sexo en los modos de socialización gay dominantes

Renaud René Boivin 
conllevaría una división espacial entre lugares, agentes y actividades. Por un lado, las formas más festivas y consumistas, sobrevisibles, suelen localizarse en el centro de las grandes ciudades; mientras que, por otro, las prácticas menos legitimadas, ligadas al sexo y a la prostitución, se emplazan en espacios periféricos de mayor discreción ${ }^{12}$. Dicha división espacial se expresa por otra parte en el 'barrio gay' con la modificación de la tipología dominante de los establecimientos comerciales destinados a una población LGBT: en Chueca, este proceso se visualiza ya a partir de mediados de los 90, con el aumento de cafés y restaurantes gays o gay friendly, abiertos de día, y se incentiva aún más en la década de los 2000, con el crecimiento relativo de tiendas, alojamientos y otros servicios destinados a la 'comunidad gay'. En cambio, los lugares de sexo y prostitución (cuartos oscuros, saunas y baños) se alejan del 'barrio gay' y de las miradas, y los hallamos más dispersos en la geografía madrileña: los nuevos lugares comerciales de sexo se instalan en barrios periféricos (tabla 5). Esta morfología urbana de los lugares de sexo es consecuente con la desexualización de la sociabilidad gay en reacción al VIH-sida (MARTEL, 2001). El repunte de saunas y cabinas de sexo en los últimos años podría tener que ver con una reconsideración del sexo entre las clases medias como una actividad sana y más segura, y con la disminución de la percepción del

Tabla 4: Evolución de los establecimientos LGBT según grandes tipos de establecimientos por barrios en Madrid (1985-2009)

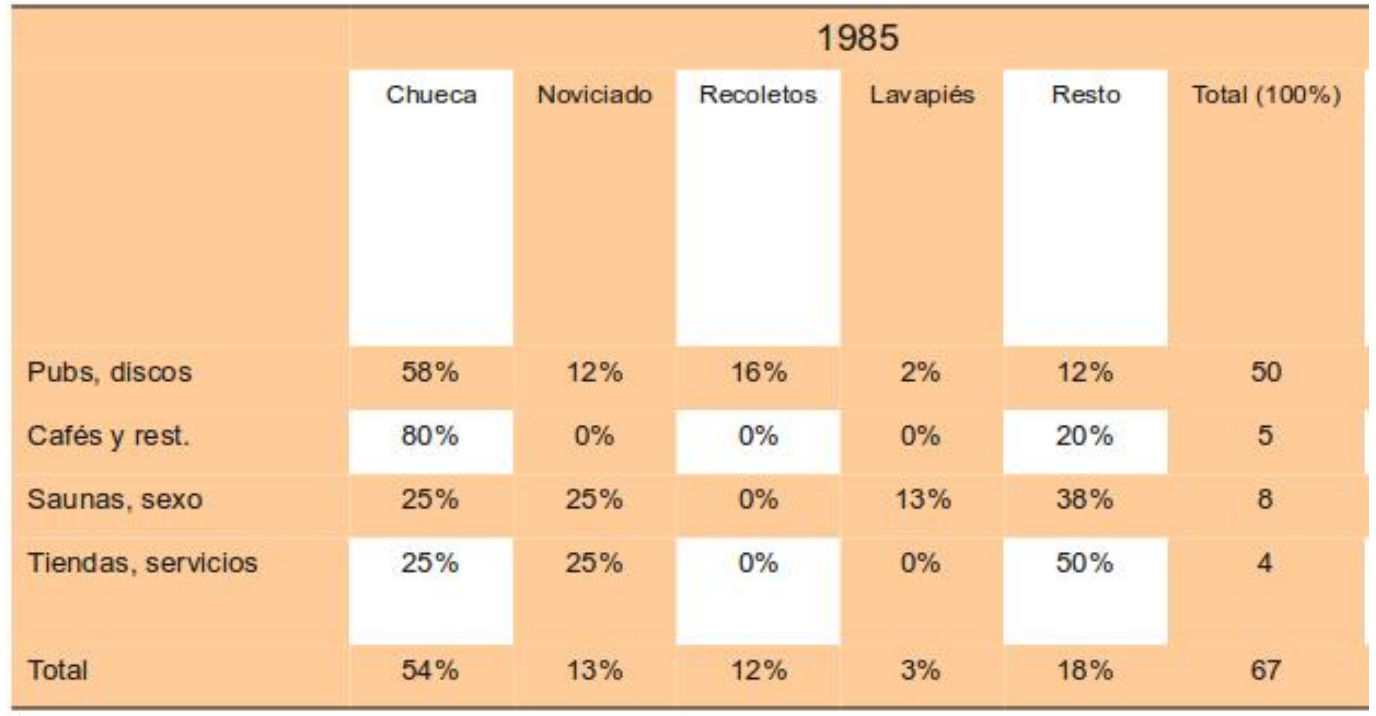

\begin{tabular}{|c|c|c|c|c|c|c|}
\hline & \multicolumn{6}{|c|}{1999} \\
\hline & Chueca & Noviciado & Recoletos & Lavapiés & Resto & Total $(100 \%)$ \\
\hline Pubs, discos & $47 \%$ & $6 \%$ & $6 \%$ & $14 \%$ & $28 \%$ & 87 \\
\hline Cafés y rest. & $50 \%$ & $9 \%$ & $0 \%$ & $6 \%$ & $34 \%$ & 32 \\
\hline Saunas, sexo & $20 \%$ & $40 \%$ & $0 \%$ & $0 \%$ & $40 \%$ & 10 \\
\hline Tiendas, servicios & $67 \%$ & $4 \%$ & $0 \%$ & $8 \%$ & $21 \%$ & 24 \\
\hline Total & $49 \%$ & $8 \%$ & $3 \%$ & $10 \%$ & $29 \%$ & 153 \\
\hline
\end{tabular}

Renaud René Boivin 


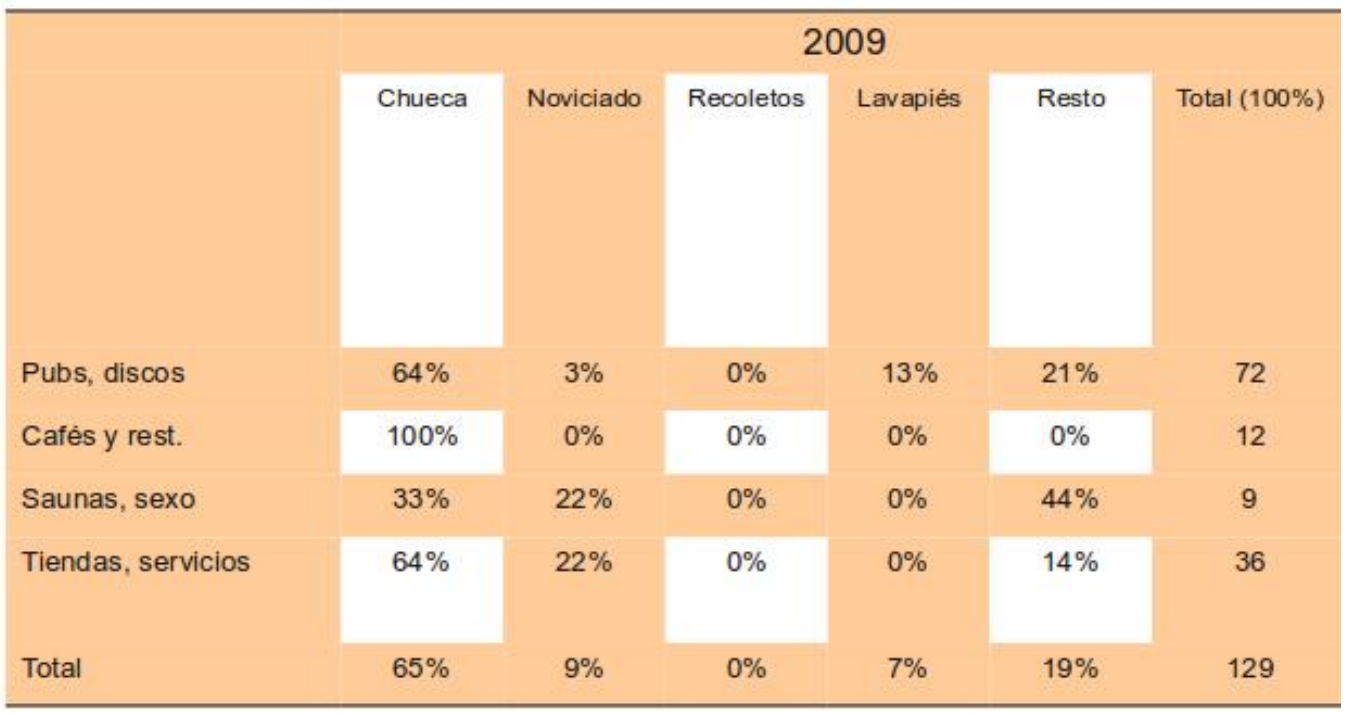

Fuente: Elaboración propia a partir de Madrid Gai (1985), Entiendes (1999) y Zero (2009)

riesgo de contraer VIH. Estos nuevos espacios suelen ser, también, más identitarios, mientras que las primeras saunas de los años 70 no eran abiertamente gays y su público era más mixto.

\section{Rehabilitación gay y rehabilitación del homosexual}

Entre finales de los años 60 y los años 90, Chueca ha pasado de ser un espacio de sexo a un espacio de la sexualidad (ver BLIDON, 2008, sobre esta distinción), en el cual la dimensión de representación toma mayor relevancia que la práctica sexual. Los bares y las discotecas gays, descritos en los años 80 (tanto por la prensa como por los propios militantes gays) como lugares de intercambio sexual furtivo, anónimo, ligado a la prostitución y al consumo de drogas ${ }^{13}$, se hacen así más luminosos y discretos; sus actividades se legalizan y se describen como prósperas. Por otra parte, en los últimos años Chueca se ha ido afirmando cada vez más como un barrio que simboliza, construye y reproduce el modelo gay, exclusivo en términos socio-culturales y económicos. Ahora bien, este mismo modelo gay de relaciones homoeróticas supone una virilización de la imagen del homosexual: Guash (1995) situaba para España la 'transición homosexual' -el paso desde unas formas de socialización no convencionales y públicas hacia modos institucionalizados en espacios cerrados, concretos e identificables - a mediados de los años 80: según él, a partir de ese momento los comerciantes siguieron las modas estadounidenses y sus modos de entender y vivir la homosexualidad fueron altamente influenciados por éstas (aparición del 'leather', etc.).

A partir de mediados de los años 90, el homosexual, antes representado con los caracteres de afeminamiento $\mathrm{y}$ travestismo, $\mathrm{y}$ en repuesta precisamente a estas imágenes vueltas degradantes, se hace gay: varonil y exitoso. La desnudez y las posturas 'pasivas' dan paso a imágenes de hombres en traje y corbata, una simbología muy ligada a la visión del homosexual como exitoso autónomo (BOIVIN, 2010a). Esta masculinización también se percibe en la hexis corporal de la población masculina que frecuenta el barrio, en el rechazo discursivo de la 'loca' y de todo lo atañe a lo femenino o derriba las fronteras de género: transexual o transgénero, travestí.

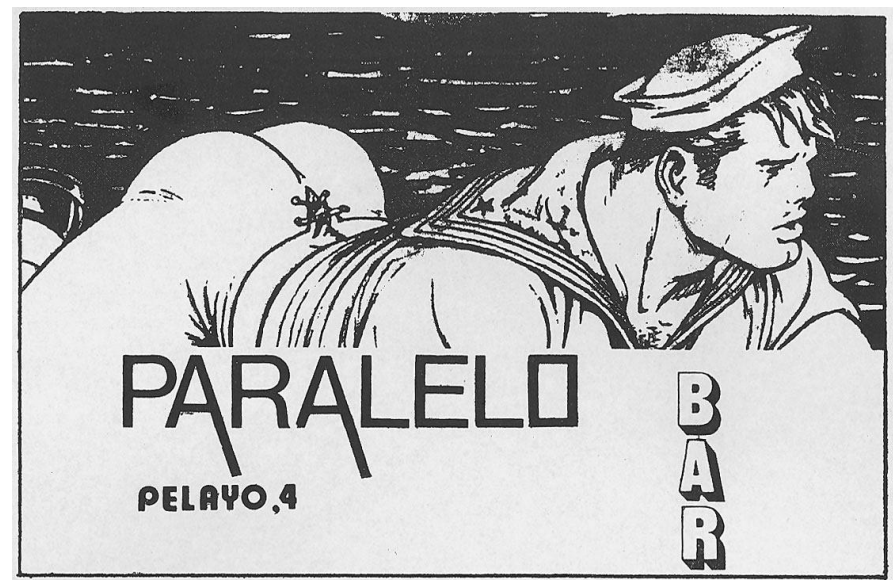

Fig. 1: Bar Paralelo, AGAMA, Madrid Gai nº2, 1983 


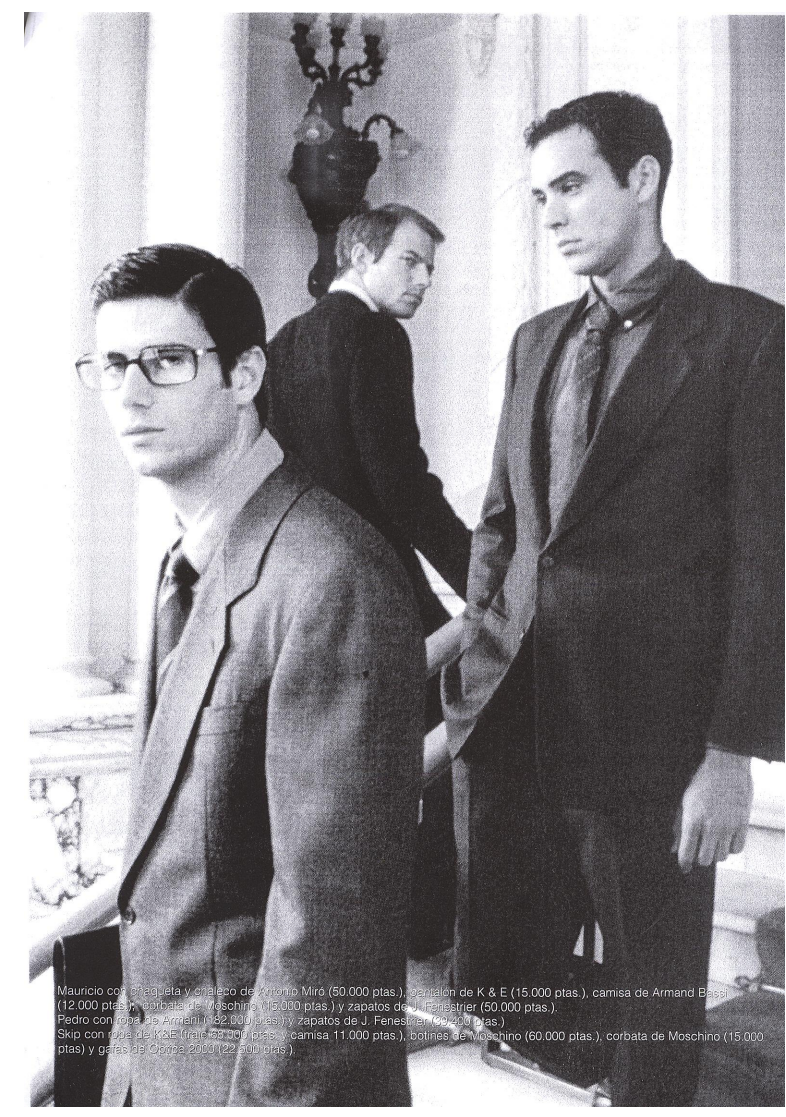

Fig. 2: Moda gay en Zero n², 1998

Sin duda, la rehabilitación de Chueca está vinculada con la presencia del tejido comercial, asociativo y con la concentración residencial gays en el barrio. Sin embargo, dicha presencia es anterior a la rehabilitación simbólica (y material) de éste. La gentrificación del barrio no es únicamente el producto de presencia homosexual. Al menos, no se trata de un efecto directo. La gentrificación de Chueca ha dependido fuertemente de la puesta en marcha de políticas públicas destinadas a dinamizar el mercado de vivienda, de un cambio de imagen del barrio a su vez propiciado por dichas políticas en lo relevante al espacio público, y vinculado a la modificación de las maneras de representar y vivir la homosexualidad, cuanto más aceptable si se acercan a los modos de vida heterosexuales y normalizados - al esconderse las prácticas sexuales y la prostitución, por ejemplo. Es así como masculinización, normalización del homosexual y gentrificación se vinculan: la rehabilitación urbana -la valorización de un espacio- sería por tanto, a la vez que producto de la participación homosexual a su revitalización residencial y comercial, una fuerte palanca para la propia rehabilitación del homosexual.
$1 \quad$ Agradezco las atentas lecturas y comentarios del historiador Enrique Esqueda Blas (Colegio de México).

2 La zona de Chueca forma parte del barrio administrativo de Justicia (Distrito Centro de Madrid). Dicho barrio está situado entre la Calle Fuencarral, el Paseo de Recoletos y la Gran Vía. Es más conocido como Chueca, nombre de la plaza principal y de la estación de Metro situada en esta última.

3 Este enlace quedó claro en la Jornada "Urban Commerce: Mercado de ideas en la gestión en materia de comercio y ciudad" (Vitoria Gasteiz, 20-09-2007), en la cual participó Beatriz Blanco, de la Oficina del Centro del Ayuntamiento de Madrid. Mili Hernández, propietaria de una librería lésbico-gay, presentó una ponencia sobre la "Revitalización del barrio de Chueca", imponiendo su propia visión del proceso..

4 Si bien desde los años 80 se publicaron varios trabajos que, sin utilizar el término, versan sobre políticas de renovación y rehabilitación y sus efectos elitizadores en barrios populares y céntricos, la literatura sobre gentrificación urbana en España es escasa y el uso de dicha noción muy reciente (véase el examen de la cuestión en: RODRIGUEZ et. al., 2002, y DUQUE, 2010). A fecha de 25 de febrero de 2011, quitando los artículos sobre ciudades extranjeras, en la base de datos del Consejo Superior de Investigaciones Científicas censamos unas 25 publicaciones españolas que recogen el término (y/o el de "elitización"). La mayoría de los trabajos son de orden teórico. Para Madrid, los trabajos consultados, además de los ya citados, han sido: García Herrera, 2001; Muñoz, 2009; Sargatal, 2000 y Vázquez, 1992. En cuanto a las referencias al espacio gay de Chueca, son aún más escasas y poco documentadas: García Escalona, 2000; Santos Solla, 2002. Mira, 2004, y Villaamil, 2004, dedican un capítulo específico al desarrollo de Chueca.

5 Los territorios son tanto países como
ciudades (FERNÁNDEZ SALINAS, 2007a y 2007b).

6 En las cantinas populares del centro de la Ciudad de México, por ejemplo, los comerciantes aprovecharon un sector en auge para atraer más clientela (BOIVIN, 2010b).

7 Carmen Vázquez (1992, p. 360 - 363) sitúa un importante boom inmobiliario en esta época: el valor del suelo y los precios de las viviendas en venta

Renaud René Boivin 
se incrementan de forma drástica a partir de 1988. La política de rehabilitación, enfocada hacia la activación del sector privado, habría incentivado tales incrementos.

8 En contraste, el incremento relativo del conjunto de viviendas principales es del $2 \%$.Cálculos propios a partir de los datos del Instituto de Estadísticas de la Comunidad de Madrid (Censos 1991 y 2001).

9 La renovada atracción del barrio de Chueca podría remontarse a los primeros años de la transición democrática. Se concretizará a principios de los años 80, durante la Movida madrileña, un movimiento cultural desestructurado.

10 Es importante tomar en cuenta la depresión económica (aumento del paro estructural, sobre todo entre los más jóvenes) que atraviesa Madrid a finales de los años 80, que en el caso del barrio de Chueca se agrava por la fuerte presencia de consumidores de heroína y el carácter territorializado de la crisis sanitaria del sida. Cf. El País, 19 - 11 - 88.

11 Cálculos propios realizados a partir de las guías incluidas en revistas gays locales. Para una descripción de la evolución del espacio gay madrileño y la génesis del barrio gay de Chueca, véase Boivin, 2010a.

12 Esta división espacial también está presente en París (REDOUTEY, 2002), Berlín (GRESILLON, 2000) $y$, en menor medida, en Ciudad de México (BOIVIN, 2012).

13 Por ejemplo, a principios de los años 80, el ambiente de Chueca quedaba descrito de la siguiente manera: "Un olor fuerte y penetrante es el primer síntoma de la violencia que allí se respira (...). El trapicheo [venta de drogas] no existe tanto en la calle como dentro de los pubs. La heroína es para muchos homosexuales una manera más de ganarse la vida y un complemento de su relación sexual" (El País, 31-0783). Diez años después, la descripción cambia radicalmente: "Pilar Cristóbal vive y trabaja en el Madrid más libertario, ese de trazado estrecho y mentes amplias" (El País, 3-11-93).

\section{Referências}

BARRADO TIMÓN, Diego. Gran ciudad y turismo en la transición postindustrial: nuevos y viejos procesos, nuevas y viejas teorías. El ejemplo del área metropolitana de Madrid. Scripta Nova. Revista Electrónica de Geografía y Ciencias Sociales, Universidad de Barcelona, v. XIV, n. 317,marzo 2010. $<$ Disponível em http://www.ub.edu/geocrit/sn/sn317.htm>.

BEAUREGARD, Robert. Voices of decline. The postwar fate of the cities. London: Routledge, 2003.

BLIDON, Marianne. Jalons pour une géographie des homosexualités. L'espace géographique, v. 37, n. 2, p. 175-189, 2008.

BOIVIN, Renaud. Chueca, du ghetto au village: la construction d'un quartier gay dans l'espace des représentations (1960-2008). Journées du Pôle Ville, 25 de enero 2010 a.

BOIVIN, Renaud. De la ambigüedad a la sobrevisibilidad: homosexualidad, género y espacio en la Ciudad de México. Revista Ciudades, Análisis de la coyuntura, teoría e historia urbana, n. 88, p. 52 59 , octubre 2010 b.

BOIVIN, Renaud. De la ambigüedad del clóset a la cultura del gueto gay. Género y homosexualidad en París, Madrid y México. La Ventana, n. 34, p. 146189, marzo 2012.

BOUTHILlETTE, Anne-Marie. The role of gay communities in gentrification: A case study of Cabbagetown, Toronto. En: WHITTLE, Stephen (ed.), The Margins of the City: Gay Men's Urban Lives. Aldershot: Ashgate Arena, 1994, p. 65 - 83.

CASTELlS, Manuel. The City and the Grassroots. Londres: E. Arnold, 1983.

CHICOINE, Nathalie; ROSE, Damaris. Usages et représentations de la centralité: le cas de jeunes employés du secteur tertiaire à Montreal. En: GRAMEYER Yves, F. DANSEREAU (Eds.). Trajectoires familiales et espaces de vie en milieu urbain. Lyon: Presses Universitaires de Lyon, 1998, p. $315-333$.

DUQUE CALVACHE, Ricardo. El concepto de gentrification en España: reflexión teórica y debate terminológico. Biblio 3W. Revista Bibliográfica de 
Geografía y Ciencias Sociales, Universidad de Barcelona, v. XV, n. 875, junio 2010.

FERNÁNDEZ SALINAS, Víctor. Visibilidad y escena gay en la ciudad española. Documents d' Anàlisi Geogràfica, n. 49, p. 139 - 160, 2007a.

FERNÁNDEZ SALINAS, Víctor. Comunidad gay y espacio en España. Boletín de la Asociación de Geógrafos Españoles, n. 43, p. 241-260, 2007b.

FERNÁNDEZ SALINAS, Víctor. ¿Un planeta fuera del armario? La visibilidad gay como objeto de estudio geográfico. Scripta Nova. Revista Electrónica de Geografía y Ciencias Sociales, v. XII, n. 270, agosto 2008 .

GARCÍA ESCALONA, Emilia. Del armario al barrio: aproximación a un nuevo espacio urbano. Anales de Geografía de la Universidad Complutense, n. 20, p. 437-449, 2000

GARCÍA HERRERA, Luz Marina. Elitización: propuesta en español para el término gentrificación. Biblio 3W. Revista Bibliográfica de geografía y ciencias sociales, Universidad de Barcelona, v. VI, n. 332 , dicembre 2001

GIRAUD, Colin. Les commerces gays et le processus de gentrification. L'exemple du quartier du Marais depuis le début des années 1980. Métropoles, n. 5, 2009.

GIRAUD, Colin. Sociologie de la gaytrification. Place et rôle des populations homosexuelles masculines dans les processus de gentrification à Paris et Montréal. 2010. Tesis de Doctorado en Sociología Urbana. Lyon: Universidad Lyon-II.

GRÉSILLON, Boris. Faces cachées de l'urbain ou éléments d'une nouvelle centralité? Les lieux de la culture homosexuelle à Berlin. L'Espace géographique, n. 4, p. $301-313,2000$.

GUASH, Óscar. La sociedad rosa. Barcelona: Anagrama, 1995.

KNOPP, Lawrence. Some theorical implications of gay involvement in an urban land market. Gender and political geography. Political geography quarterly, vol. 9, n. 4, p. 337-352, 1990.

LAURIA, Mickey; KNOPP, Lawrence. Toward an Analysis of the Role of Gay Communities in the
Urban Renaissance. Urban Geography, v. 6, n. 2, p.152-169, 1985.

LEY, David. The new middle class and the remaking of the central city. Oxford: Oxford University Press, 1996.

MARTEL, Frédéric. Le rose et le noir. Les homosexuels en France depuis 1968. Paris: Seuil, 2001 .

MIRA, Alberto. De Sodoma a Chueca: historia cultural de la homosexualidad en España, 19141990. Madrid: Egales, 2004.

MUÑOZ CARRERA, Óscar. El proceso de gentrificación en el municipio de Madrid, 1996-2001. En: XIV Congreso Nacional de Sociología en Castilla La Mancha, Almagro, nov. 2009.

OLANO DOMÍNGUEZ, Antonio. Guía secreta de Madrid. Madrid: Sedmay, 1975.

POLLAK, Michael. L'homosexualité masculine ou le bonheur dans le ghetto?. Communications, n. 35, p. $37-55,1982$

REDOUTEY, Emmanuel. Géographie de l'homosexualité à Paris, 1984-2000. Urbanisme, n. 325, p. 59-63, 2002.

SARGATAL BATALLER, María Alba. El estudio de la gentrificación. Biblio 3W. Revista Bibliográfica de Geografía y Ciencias Sociales, n. 228, mayo 2000.

VAZQUEZ VARELA, Carmen. Urban policies and gentrification trends in Madrid's inner city. Netherlands' Journal of Housing \& Built Environment, v. 7, n. 4, p.357-376, 1992.

VILLAAMIL, Fernando. La transformación de la identidad gay en España. Madrid: Catarata, 2004.

Recebido em 30 de abril de 2012. Aceito em 28 de agosto de 2012.

Renaud René Boivin 